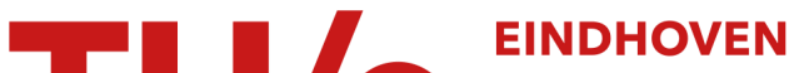 \\ UNIVERSITY OF \\ TECHNOLOGY
}

\section{Symmetry of periodic structures in a 3D mixing cavity flow}

Citation for published version (APA):

Galaktionov, O. S., Anderson, P. D., \& Peters, G. W. M. (2000). Symmetry of periodic structures in a 3D mixing cavity flow. Physics of Fluids, 12(2), 469-471. https://doi.org/10.1063/1.870328

DOI:

10.1063/1.870328

Document status and date:

Published: 01/01/2000

\section{Document Version:}

Publisher's PDF, also known as Version of Record (includes final page, issue and volume numbers)

\section{Please check the document version of this publication:}

- A submitted manuscript is the version of the article upon submission and before peer-review. There can be important differences between the submitted version and the official published version of record. People interested in the research are advised to contact the author for the final version of the publication, or visit the $\mathrm{DOI}$ to the publisher's website.

- The final author version and the galley proof are versions of the publication after peer review.

- The final published version features the final layout of the paper including the volume, issue and page numbers.

Link to publication

\section{General rights}

Copyright and moral rights for the publications made accessible in the public portal are retained by the authors and/or other copyright owners and it is a condition of accessing publications that users recognise and abide by the legal requirements associated with these rights.

- Users may download and print one copy of any publication from the public portal for the purpose of private study or research.

- You may not further distribute the material or use it for any profit-making activity or commercial gain

- You may freely distribute the URL identifying the publication in the public portal.

If the publication is distributed under the terms of Article 25fa of the Dutch Copyright Act, indicated by the "Taverne" license above, please follow below link for the End User Agreement:

www.tue.nl/taverne

Take down policy

If you believe that this document breaches copyright please contact us at:

openaccess@tue.nl

providing details and we will investigate your claim. 


\title{
Symmetry of periodic structures in a 3D mixing cavity flow
}

\author{
O. S. Galaktionov, P. D. Anderson, and G. W. M. Peters \\ Dutch Polymer Institute, Materials Technology, Eindhoven University of Technology, WH 0.132, \\ P.O. Box 513, 5600 MB Eindhoven, The Netherlands
}

(Received 9 August 1999; accepted 28 October 1999)

Symmetry concepts are applied to analyze three-dimensional time-periodic mixing Stokes flows in a cubic domain. Usage of simple map algebra, developed by Franjione et al. [Phys. Fluids A 11, 1772-1783 (1989); Philos. Trans. R. Soc. London, Ser. A 338, 301-323 (1992)], allows us to reveal the symmetry in the arrangement of periodic points in such a flow. Symmetries reveal essential features of the underlying physics, and with manipulation of symmetries mixing protocols can be made efficient over the entire flow domain. (C) 2000 American Institute of Physics.

[S1070-6631(00)01602-0]

In the recently published article by Anderson et al. ${ }^{1}$ it was demonstrated that in three-dimensional time-periodic flows periodic points (i.e., material points that return to their original position after $n$ periods) can form structures (lines), and a computational technique to find these lines was described. Periodic lines were found and classified for different flows in brick-shaped domains, where the fluid motion was generated by consecutive sliding of two opposite cavity walls. The detected periodic lines exhibited remarkable symmetry, which in some cases was apparent and well understood. However, in the example of a four-step mixing protocol in a cubic cavity with crossed directions of the wall movements, the symmetry was not properly revealed and explained. However, we found that using the flow symmetry relations and a mapping technique analogous to that developed by Franjione et al. ${ }^{2}$ it is possible to show theoretically what type of symmetry the periodic structures in this flow should necessarily possess.

The flow under consideration is a time-periodic Stokes flow (Reynolds number $\mathrm{Re} \ll 1$ ) in a cubic domain, defined as $|x|<1,|y|<1,|z|<1$ in dimensionless coordinates. Two opposite walls $y= \pm 1$ can slide in $x$ and $z$ directions. The protocol of the wall motion consists of four steps. During each step only one wall is moving, wall displacements during different steps are equal to each other. The scheme of the protocol is presented in Fig. 1. This is one of simplest threedimensional mixing protocols for such a simple domain that has zero total displacement of all movable walls after a full cycle. Such protocols are of interest because of their anticipated experimental feasibility, as the movable walls can be made of rigid transparent plates (avoiding usage of circular belts) giving better optical access to the flow domain from different viewpoints.

According to Franjione $e t a .^{2}$ we introduce maps describing the fluid displacement on every single step. The notations are as follows: " $\mathbf{F}$ " and "B" denote front or back wall motion, while the subscript denotes the direction of the wall motion ("rr," "l,", "u" and "d" stand for "right," "left," "up" and "down" respectively). Thus, for example, the operator $\mathbf{F}_{\mathbf{r}}$ describes the results of the front wall ( $y$
$=-1)$ moved to the right. Using these maps the protocol under study can be written as

$$
\mathbf{P}=\mathbf{B}_{\mathrm{d}} \mathbf{F}_{\mathrm{l}} \mathbf{B}_{\mathrm{u}} \mathbf{F}_{\mathrm{r}},
$$

where the rightmost operator is acting first. The symmetry operators $\mathbf{S}_{x}, \mathbf{S}_{y}$ and $\mathbf{S}_{x z}$ can be introduced:

$$
\begin{aligned}
& \mathbf{S}_{x}(x, y, z)=(-x, y, z), \\
& \mathbf{S}_{y}(x, y, z)=(x,-y, z), \\
& \mathbf{S}_{x z}(x, y, z)=(z, y, x) .
\end{aligned}
$$

In addition the operator $\widetilde{\mathbf{S}}=\mathbf{S}_{y} \mathbf{S}_{x z}$ is defined as

$$
\begin{aligned}
& \widetilde{\mathbf{S}}(x, y, z)=(z,-y, x), \\
& \widetilde{\mathbf{S}}=\mathbf{S}_{y} \mathbf{S}_{x z}=\mathbf{S}_{x z} \mathbf{S}_{y} .
\end{aligned}
$$

This operator, in fact, describes a rotation by $180^{\circ}$, i.e., axial symmetry, around the line defined by $y=0, x-z=0$. It is obvious that $\widetilde{\mathbf{S}} \widetilde{\mathbf{S}}=\mathbf{1}$ and, thus, $\widetilde{\mathbf{S}}^{-1}=\widetilde{\mathbf{S}}$, where $\mathbf{1}$ is the identity operator.

Using the symmetry of the flow domain and the symmetry of the velocity field it is possible to express all operators used in protocol $\mathbf{P}$ through a single basic map $\mathbf{F} \equiv \mathbf{F}_{\mathbf{r}}$ and symmetry operators as follows:

$$
\begin{aligned}
& \mathbf{F}_{\mathbf{r}}=\mathbf{F}, \quad \mathbf{F}_{\mathbf{l}}=\mathbf{F}^{-1}, \\
& \mathbf{B}_{\mathbf{u}}=\widetilde{\mathbf{S}} \mathbf{F} \widetilde{\mathbf{S}}, \quad \mathbf{B}_{\mathbf{d}}=\mathbf{B}_{\mathbf{u}}{ }^{-1}=\widetilde{\mathbf{S}} \mathbf{F}^{-1} \widetilde{\mathbf{S}} .
\end{aligned}
$$

Note that, for practical purposes, the inverse map $\mathbf{F}^{-1}$ can also be presented as $\mathbf{F}^{-1}=\mathbf{S}_{x} \mathbf{F} \mathbf{S}_{x}$.

Using the relations (7) the expression (1) for the protocol $\mathbf{P}$ can be rewritten as

$$
\mathbf{P}=\widetilde{\mathbf{S}} \mathbf{F}^{-1} \widetilde{\mathbf{S}} \mathbf{F}^{-1} \widetilde{\mathbf{S}} \mathbf{F} \widetilde{\mathbf{S}} \mathbf{F} .
$$

The inverse protocol $\mathbf{P}^{-1}$ then will look as follows (operators are rewritten in inverse order and replaced by their inverses, taking into account that $\widetilde{\mathbf{S}}^{-1}=\widetilde{\mathbf{S}}$ ):

$$
\mathbf{P}^{-1}=\mathbf{F}^{-1} \widetilde{\mathbf{S}} \mathbf{F}^{-1} \widetilde{\mathbf{S}} \mathbf{F} \widetilde{\mathbf{S}} \mathbf{F} \widetilde{\mathbf{S}} .
$$




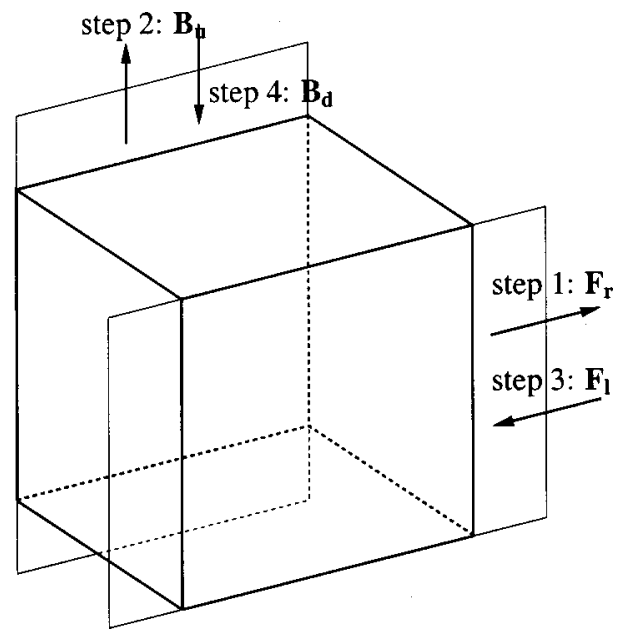

FIG. 1. Scheme of the successive motion of the cavity walls constituting the mixing protocol $\mathbf{P}$.

From (8) and (9) it follows that the protocol $\mathbf{P}$ and its inverse $\mathbf{P}^{-1}$ possess the following symmetry relations:

$$
\mathbf{P}^{-1}=\widetilde{\mathbf{S}} \mathbf{P} \widetilde{\mathbf{S}}, \quad \mathbf{P}=\widetilde{\mathbf{S}} \mathbf{P}^{-1} \widetilde{\mathbf{S}} .
$$

In terms used by Franjione and Ottino ${ }^{3}$ it means that the map $\mathbf{P}$ has a time-reversal symmetry $\widetilde{\mathbf{S}}$. The same symmetry holds for the maps $\mathbf{P}^{n}$ for $n>1$, which can be shown as follows. If $\mathbf{P}^{k}$ possesses the symmetry $\widetilde{\mathbf{S}}$, which means that $\mathbf{P}^{-k}=\widetilde{\mathbf{S}} \mathbf{P}^{k} \widetilde{\mathbf{S}}$, then the same is true for $k+1$ :

$$
\begin{aligned}
\mathbf{P}^{-(k+1)} & =\mathbf{P}^{-1} \mathbf{P}^{-k} \\
& =\underbrace{\widetilde{\mathbf{S}} \mathbf{P} \mathbf{S}}_{\mathbf{P}^{-1}} \underbrace{\widetilde{\mathbf{S}} \mathbf{P}^{k}}_{\mathbf{P}^{-k}} \widetilde{\mathbf{S}} \\
& =\underbrace{\widetilde{\mathbf{S}} \widetilde{\mathbf{S}}}_{\mathbf{\mathbf { S }}} \mathbf{P}^{k} \widetilde{\mathbf{S}}=\widetilde{\mathbf{S}} \mathbf{P} \mathbf{P}^{k} \widetilde{\mathbf{S}}=\widetilde{\mathbf{S}} \mathbf{P}^{k+1} \widetilde{\mathbf{S}} .
\end{aligned}
$$

Relation (11) forms the step of the induction with (10) being its base for $k=1$. Thus, for any integer $n \geqslant 1$,

$$
\mathbf{P}^{-n}=\widetilde{\mathbf{S}} \mathbf{P}^{n} \widetilde{\mathbf{S}} \quad \text { and } \quad \mathbf{P}^{n}=\widetilde{\mathbf{S}} \mathbf{P}^{-n} \widetilde{\mathbf{S}} .
$$

The relations (12) and reversibility of the Stokes flow gives the possibility to reveal the symmetry that periodic structures of the flow under study must necessarily possess. Namely, it is proven that periodic structures of any order (or the isolated points, if any) should be arranged symmetrically around the axis $y=0, x-z=0$ (see Fig. 2).

Theorem: If $\mathbf{a}$ is a periodic point of $n$th order of the flow, described by the protocol $\mathbf{P}$ (1), then the point $\widetilde{\mathbf{S a}}$, which is symmetrical to it with respect to the axis $y=0, x$ $-z=0$, is also a $n$th order periodic point of the same flow.

Proof: By definition, the point $\mathbf{a}$ is a periodic point of $n$th order of the map $\mathbf{P}$ if $\mathbf{P}^{n} \mathbf{a}=\mathbf{a}$ and $\mathbf{P}^{k} \mathbf{a} \neq \mathbf{a}$ for any $1 \leqslant k$ $<n$. As the Stokes flow is quasi-stationary, it can be reversed, and the same point a remains periodic for inverse protocol: $\mathbf{P}^{-n} \mathbf{a}=\mathbf{a}$. Then the point $\widetilde{\mathbf{S}} \mathbf{a}$ is mapped as follows:

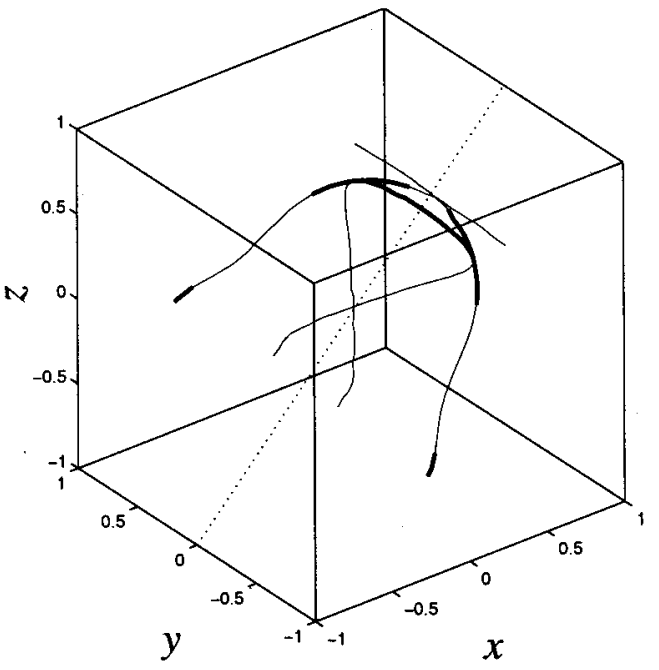

FIG. 2. Periodic lines in the central part of the cavity (see Anderson et al. ${ }^{1}$ ). The displacement of the moving wall during each step is equal to 2.5 of the length of the cube edge. Elliptic (stable) periodic lines are plotted thick, hyperbolic (unstable) are shown thin. The dotted line denotes the axis of symmetry (for further explanation, see text).

$$
\mathbf{P}^{n} \widetilde{\mathbf{S}} \mathbf{a}=\underbrace{\widetilde{\mathbf{S}}}_{\mathbf{1}} \widetilde{P^{n}} \widetilde{\mathbf{S}} \mathbf{a}=\underbrace{\widetilde{\mathbf{S}} \mathbf{P}^{n} \tilde{\mathbf{S}}}_{\mathbf{P}^{-n}} a=\widetilde{\mathbf{S}} \mathbf{P}^{-n} \mathbf{a}=\widetilde{\mathbf{S}} \mathbf{a} .
$$

It can be shown in the same way that $\mathbf{P}^{k} \mathbf{a} \neq \mathbf{a}$ for $1 \leqslant k$ $<n$. Thus, $\widetilde{\mathbf{S}} \mathbf{a}$ is a periodic point of $n$th order of the protocol P.

Figure 2 shows the example of the periodic lines of the first order, found in Anderson et al., ${ }^{1}$ for the flow with the dimensionless wall displacement equal to 2.5. This system of periodic lines does exhibit the discussed type of symmetry. The elliptic line in the middle is actually crossing the axis of symmetry. It is interesting to note the difference in the type of symmetry observed by Franjione et $a .^{2}$ for twodimensional cavity flows and the symmetry discussed in Anderson et al. ${ }^{1}$ and the current work for a threedimensional flow. While Franjione et $a .^{2}$ encountered only reflectional symmetries, the flow and the periodic structures discussed here possess rotational (orientation preserving) symmetry. Note that Franjione and Ottino $^{3}$ provided some examples of more complex two-dimensional flows that exhibit orientation-preserving symmetries.

The mapping algebra, introduced by Franjione et $a l^{2}$ for the analysis of two-dimensional mixing flows in rectangular cavity, was extended and applied to a three-dimensional mixing flow in a cubic domain. It allowed us to find the symmetry that periodic structures in the examined flow should possess. It is in full agreement with numerical results recently published by Anderson et al., ${ }^{1}$ where this kind of symmetry was left unexplained. The same technique can be utilized for the analysis of different classes of mixing protocols. After the symmetry of the simplest flow protocols is revealed, the symmetry manipulation recursive techniques described by 
Franjione and Ottino ${ }^{3}$ offer a method to construct more efficient mixing protocols.

${ }^{1}$ P. D. Anderson, O. S. Galaktionov, G. W. M. Peters, F. N. van de Vosse, and H. E. H. Meijer, "Analysis of mixing in three-dimensional timeperiodic cavity flows,” J. Fluid Mech. 386, 149-166 (1999).
${ }^{2}$ J. G. Franjione, C.-W. Leong, and J. M. Ottino, "Symmetries within chaos: A route to effective mixing," Phys. Fluids A 11, 1772-1783 (1989).

${ }^{3}$ J. G. Franjione and J. M. Ottino, "Symmetry concepts for the geometric analysis of mixing flows," Philos. Trans. R. Soc. London, Ser. A 338, 301-323 (1992). 